\title{
Physical, Chemical and Morphological Studies of Spore Coat of Bacillus subtilis
}

\author{
By Y. HIRAGI \\ Institute for Chemical Research, Kyoto University, Gokasho, \\ Uji, Kyoto-Fu, 6I I, Japan
}

(Accepted for publication 20 March 1972)

\begin{abstract}
SUMMARY
Spore coat of Bacillus subtilis ATCC605I was fractionated as described by Kondo \& Foster (1967). X-ray diffraction, infrared spectra, amino acid analyses and $N$-terminal amino acid studies showed that most of the fractions resembled each other in physical and chemical structure and constituents. Electron micrographs of sections and shadowed replicas of the coat fractions at various stages showed that the inner part of the coat disappeared during treatment; no drastic morphological change was observed throughout the fractionation.

The amounts of cystine in the coat and the coat fractions were less than in keratins. This result and solubilizing experiments suggested that the spore coat does not chemically resemble keratins.
\end{abstract}

\section{INTRODUCTION}

Studies of the physical, chemical and morphological structure of the spore coat will be useful for understanding mechanisms of the spore's resistance and dormancy. Chemically, the spore coat is composed mainly of polypeptides or proteins (Strange \& Dark, I956; Salton \& Marshall, 1959; Warth, Ohye \& Murrell, I963; Murrell, 1967). Morphologically, coats are considered to be of at least two layers (Warth et al. 1963; Murrell, 1967; Gould \& Hurst, 1969). Because of the morphological complexity, attempts were made to separate individual layers of the spore coats, obtaining fractions on which chemical and morphological investigations were reported (Kondo \& Foster, 1967).

Publications have hitherto assumed that all spore coats have common physical and chemical properties. The morphological structure of the spore coat, however, differs greatly in different species (Holt \& Leadbetter, 1969), bringing in question the generality of the properties of spore coats. Close investigations of the chemical and physical characteristics in each bacterial species, and comparison of the results, are necessary to solve this problem. This paper describes results obtained with a single strain, Bacillus subtilis ATcc6051.

\section{METHODS}

Bacteriological. Bacillus subtilis ATCC605I was used throughout this study. The bacteria were grown at $37^{\circ} \mathrm{C}$ in 201 lots of medium in 251 Marubishi MRT-2 fermenters with silicone antifoam. The nutrient broth medium used was prepared as follows: $300 \mathrm{~g}$ of sliced potato/I 1 of medium was boiled and filtered with cotton gauze to prepare potato stock, to which $5 \mathrm{~g}$ of beef extract (Kyokuto Pharmaceutical Inc., Tokyo, Japan) and $5 \mathrm{~g}$ of polypeptone (Daigo Chemical Inc., Osake, Japan) were added; the final $\mathrm{pH}$ was adjusted to $7^{\circ} 0$. 


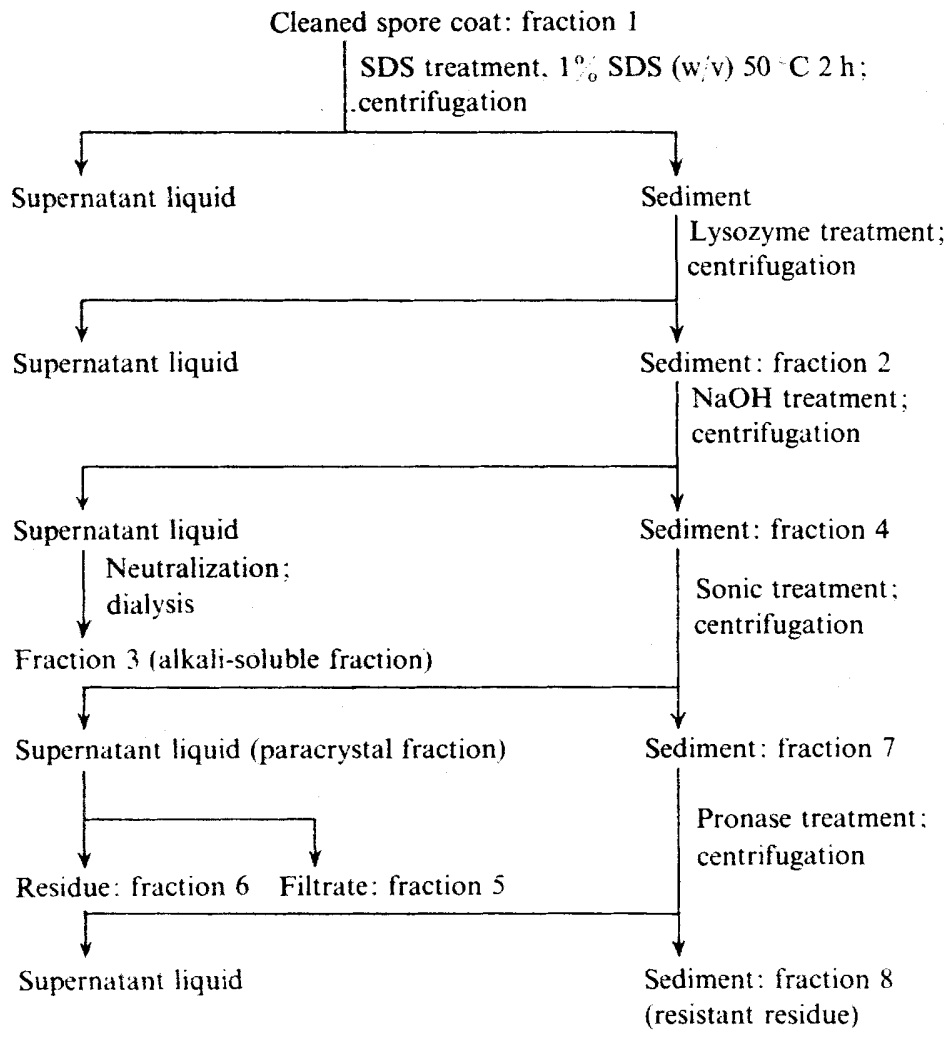

Fig. I. Scheme for fractionation of the spore coat. Designation of the fractions by Kondo \& Foster (1967) is shown in parentheses. Details of the treatments are shown in the text. Centrifugation was carried out at $13000 \mathrm{~g}$ for $15 \mathrm{~min}$.

After 7 to Io days of incubation with vigorous aeration, spores with a few vegetative cells were collected by centrifugation and washed with deionized water. After removal of vegetative cells by the 2-phase Y system of Sacks \& Alderton (I96I), the spores were washed ten times with deionized water, lyophilized, and stored in a desiccator.

Preparation of spore coats. Spore coats were obtained by mechanical rupture of the spores with glass beads of $0.1 \mathrm{I}$ to $0.12 \mathrm{~mm}$ diameter in a Braun cell disintegrator, chilled by the flow of carbon dioxide gas. After 10 to $15 \mathrm{~min}$ of shaking, no intact spore was microscopically visible. The beads were removed by decanting and gentle centrifugation (slower than 500 rev./min). The supernatant coat fragments were washed by centrifugation at $13000 \mathrm{~g}$ five times in saline (0.15 M) and five times in distilled and deionized water. Further washing was performed by successive treatment of the coat fragments with acetone, ethanol, chroloform + diethyl ether $(2: \mathrm{I}, \mathrm{v} / \mathrm{v})$, hot water, and $\mathrm{r} \%(\mathrm{w} / \mathrm{v})$ sodium dodecyl sulphate (SDS) at room temperature for $30 \mathrm{~min}$ at $\mathrm{pH} 9 \cdot 0$. Finally the coat fragments were dialysed against distilled and deionized water, lyophilized and stored in a desiccator.

Fractionation of spore coats. The spore coats were fractionated by the method of Kondo \& Foster (1967) modified to filter the 'paracrystal fraction' through a Millipore membrane filter (Millipore Inc., Bedford, Massachusetts, U.S.A.) of $0.3 \mu \mathrm{m}$ pore size. The sequence of treatments and the resulting fractions are shown in Fig. $I$.

Chemical. Amino acid compositions were determined using a JLC-3BC liquid chromato- 
graph apparatus (JEOL, Akishima, Tokyo, Japan), after acid hydrolysis with constant boiling point $\mathrm{HCl}$ (b.p. I $10^{\circ} \mathrm{C}$; about $6 \mathrm{~N}$ ) in a sealed tube at $110{ }^{\circ} \mathrm{C}$ for $20 \mathrm{~h}$.

$N$-Terminal amino acids were identified by dinitrophenylation with fluorodinitrobenzene. After the acid hydrolysis, dinitrophenyl amino acids (DNP-amino acids) were separated by two dimensional thin-layer chromatography (t.l.c.) on Kieselgel GF $_{254}$ (Merck Ag., Darmstadt, Germany), using toluene + pyridine + ethylenechlorohydrin $+0.8 \mathrm{~N}$-ammonia $(100: 30: 60: 60, \mathrm{v} / \mathrm{v})$ for the first development and chloroform + methanol+glacial acetic acid $(95: 5: \mathrm{I}, \mathrm{v} / \mathrm{V})$ for the second.

Contents of $\mathrm{C}, \mathrm{H}, \mathrm{N}, \mathrm{P}$ and $\mathrm{S}$ in the samples were determined by elemental analysis at the Centre of Elemental Analysis of Kyoto University.

$X$-ray diffraction. Debye-Scherrer powder diffractiometries were carried out by the use of a Norelco X-ray diffraction apparatus with nickel-filtered $\mathrm{Cu}-\mathrm{K} \alpha$ radiation.

Infrared absorption spectra. Coat fractions in $\mathrm{KBr}$ pellets were measured in Perkin-Elmer model $52 \mathrm{I}$ spectrophotometer.

Electron microscopy. Photographs were taken in a JEM-7A electron microscope (JEOL, Akishima, Tokyo, Japan). Coat fractions were fixed with osmium tetroxide or glutaraldehyde, embedded in epoxy resin, and sectioned. The specimens were so well contrasted that no more staining procedure was needed. Coat fractions were also shadowed with platinum + paladium $(80: 20, \mathrm{w} / \mathrm{w})$ after coating with carbon.

\section{RESULTS}

Decrease in weight of the coat fractions. Starting with $100 \mathrm{mg}$, the purified spore coat was treated successively with: $\mathrm{I} \%(\mathrm{w} / \mathrm{v}) \mathrm{SDS}$ at $50^{\circ} \mathrm{C}$ for $2 \mathrm{~h}$; lysozyme, $8 \mathrm{mg}$ in $30 \mathrm{ml} \mathrm{o.I} \mathrm{M-}$ sodium phosphate buffer, $\mathrm{pH} 7 \cdot 0$, for $24 \mathrm{~h}$ at $37^{\circ} \mathrm{C}$; $0.06 \mathrm{~N}-\mathrm{NaOH}$ for $3 \mathrm{~h}$ at $50^{\circ} \mathrm{C}$; sonication in water for 6 min at power setting 8 with a type 4250 sonicator (Kaijo Electric Inc., Tokyo, Japan); and finally pronase (Kaken Chemical Inc., Tokyo), $10 \mathrm{mg}$ in $40 \mathrm{ml} \mathrm{O} \cdot \mathrm{I}$ Mtris buffer, $\mathrm{pH} 8 \cdot 0$, for $24 \mathrm{~h}$ at $50^{\circ} \mathrm{C}$. The insoluble part of the residue at each step was centrifuged at $13000 \mathrm{~g}$, and washed with distilled and deionized water. After lyophilization, the weight of the residue was measured. The results, shown in Table I, demonstrate that the treatment with lysozyme did not give a decrease in weight of the coat fraction, presumably because the material digestible by lysozyme was removed by hot SDS treatment. In other reatments, the weight loss of the coat fractions did not exceed $15 \%$ of the original weight. No treatment dissolved the coat substantially.

$X$-ray diffraction of the coat fractions. The results of the X-ray diffraction of the coat fracions are shown in Fig. 2, where all the patterns except fraction 5 are quite similar to those of revious studies (Kadota \& Iijima, I965; Kadota, Iijima \& Uchida, I965). Solubilized ractions 3 and 6 , and residue fractions $2,4,7$ and 8 exhibited very similar patterns. They lad two sharp peaks, which often overlapped each other, at about $2 \theta=8 \cdot 8^{\circ}$ ( $\left.\mathrm{I} \cdot 0 \mathrm{r} \mathrm{nm}\right)$ ind $9.4^{\circ}(0.94 \mathrm{~nm})$, and a broad peak at about $20^{\circ}(0.44 \mathrm{~nm})$.

Although X-ray diffraction patterns of the coats and coat fractions obtained so far were oo noisy for them to be assigned to any known material, they were useful for demonstrating he difference in structure. Fig. 2 indicates that most of the fractions were of a structure imilar to that of the coat; only fraction 5 was different and this fraction had the same microcopic appearance as the 'paracrystal solid' shown in Fig. I to 4 of the article of Kondo \& Foster (1967). Examination of the fractions in an electron microscope showed that fraction 5 vas burned down by the electron beam, whereas other fractions preserved their shapes and ıppearances. 

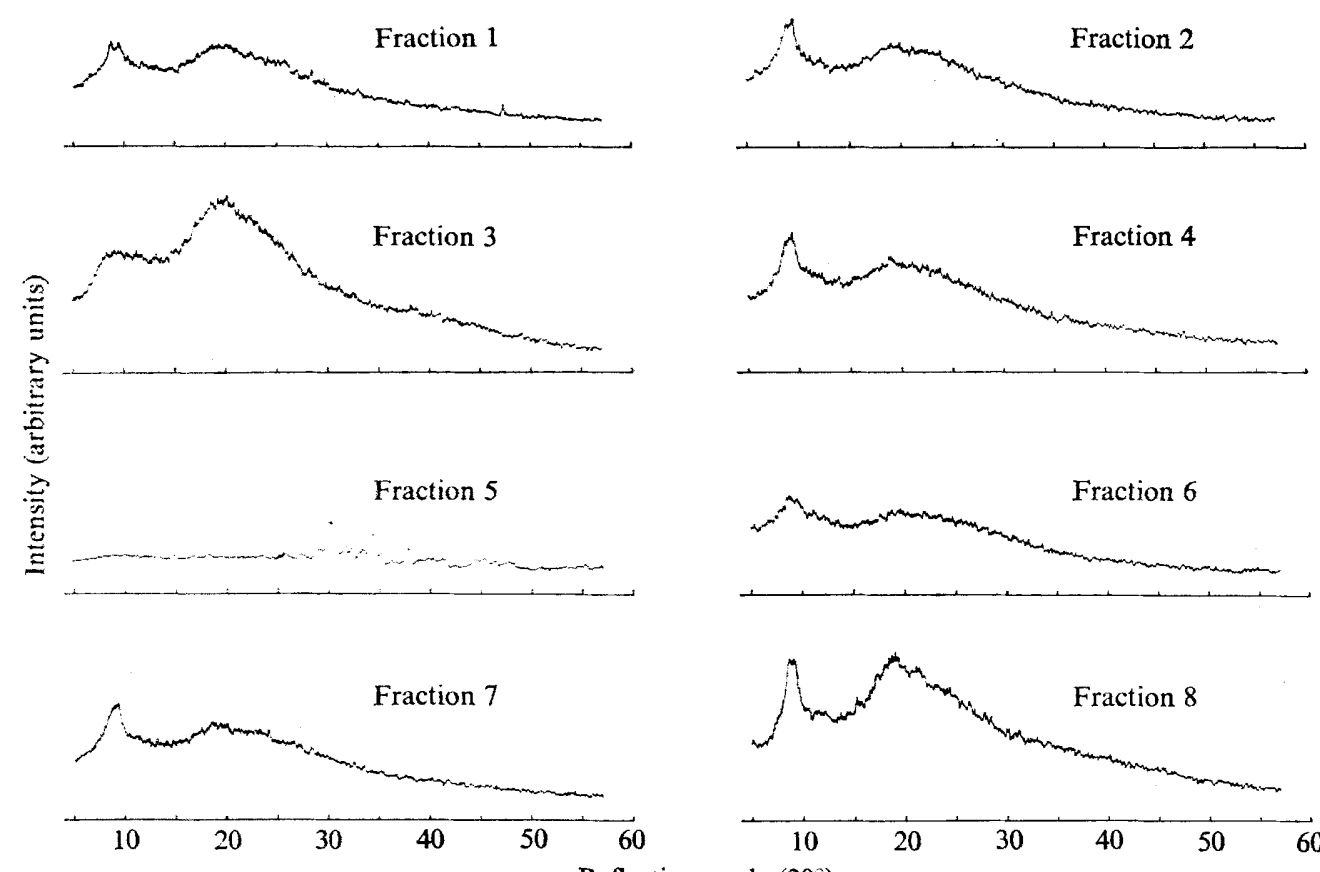

Reflection angle $\left(20^{\circ}\right)$

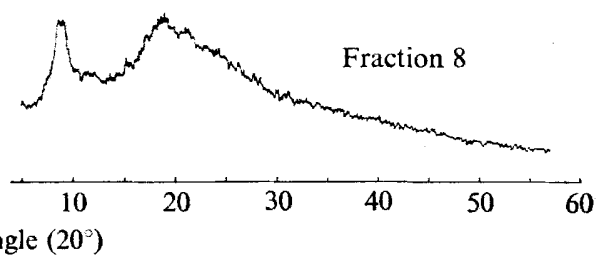

Fig. 2. X-ray diffraction patterns of the coat fractions with $\mathrm{Cu}-\mathrm{K} \alpha$ radiation. Diffractometries were carried out with the following conditions: applied voltage, $45 \mathrm{kV}$; current, ro $\mathrm{mA}$; divergence slit, $\mathrm{I}^{\circ}$; scale factor, 4 ; multiplier, $\times \mathrm{I}$; time constant, $8 \mathrm{~s}$; scanning speed, $\mathrm{I}^{\circ} / \mathrm{s}$; chart drive speed, $0.5 \mathrm{in} / \mathrm{s}$.

Table I. Decrease in weights of coat fractions by successive chemical and physical treatments

$\begin{array}{lcc}\text { Treatment* } & \begin{array}{c}\text { Decrease in weight } \\ (\% \text { of original) } \dagger\end{array} & \begin{array}{c}\text { Probable error } \\ (\%)\end{array} \\ \text { SDS } & 14 \cdot 6 & \pm 0 \cdot 8 \\ \text { Lysozyme } & -0.3 & \pm 1 \cdot 7 \\ \text { Alkali } & 11 \cdot 7 & \pm 2 \cdot 3 \\ \text { Sonic } & 10 \cdot 4 & \pm 2 \cdot 5 \\ \text { Pronase } & 13.6 & \pm 2 \cdot 2 \\ \text { Residue } \$ & 50 \cdot 0 & \pm 1 \cdot 4 \\ & \text { * For details see text. } & \\ & + \text { Mean values of four runs. } \\ & + \text { Residue of pronase treatment. }\end{array}$

Infrared spectra of coat fractions. As expected from the complicated chemical compositions of the coat and coat fractions (Warth et al. 1963; Kondo \& Foster, 1967), the infrared (i.r.) spectra did not show a simple pattern but contained many peaks difficult to assign (Fig. 3). However, absorptions common to the coat fractions at amide $I$ (at about $1650 \mathrm{~cm}^{-1}$, $\mathrm{C}=\mathrm{O}$ stretching) and amide II (at about $1530 \mathrm{~cm}^{-1}$, NH deformation) which are key bands for polypeptides or amino acids (Elliot, 1954; Asai, Tsuboi, Shimanouchi \& Mizushima, 1955; Miyazawa \& Blout, 196I), were found, together with a large peak near $3300 \mathrm{~cm}^{-1}$ assigned as amide A (NH stretching of polypeptide in trans form). Peaks near $1365 \mathrm{~cm}^{-1}$ ( $\mathrm{CH}_{3}$ symmetry), $1435 \mathrm{~cm}^{-1}$ ( $\mathrm{CH}_{3}$ antisymmetry), $1225 \mathrm{~cm}^{-1}$ (amide III), $1080 \mathrm{~cm}^{-1}$ (not 

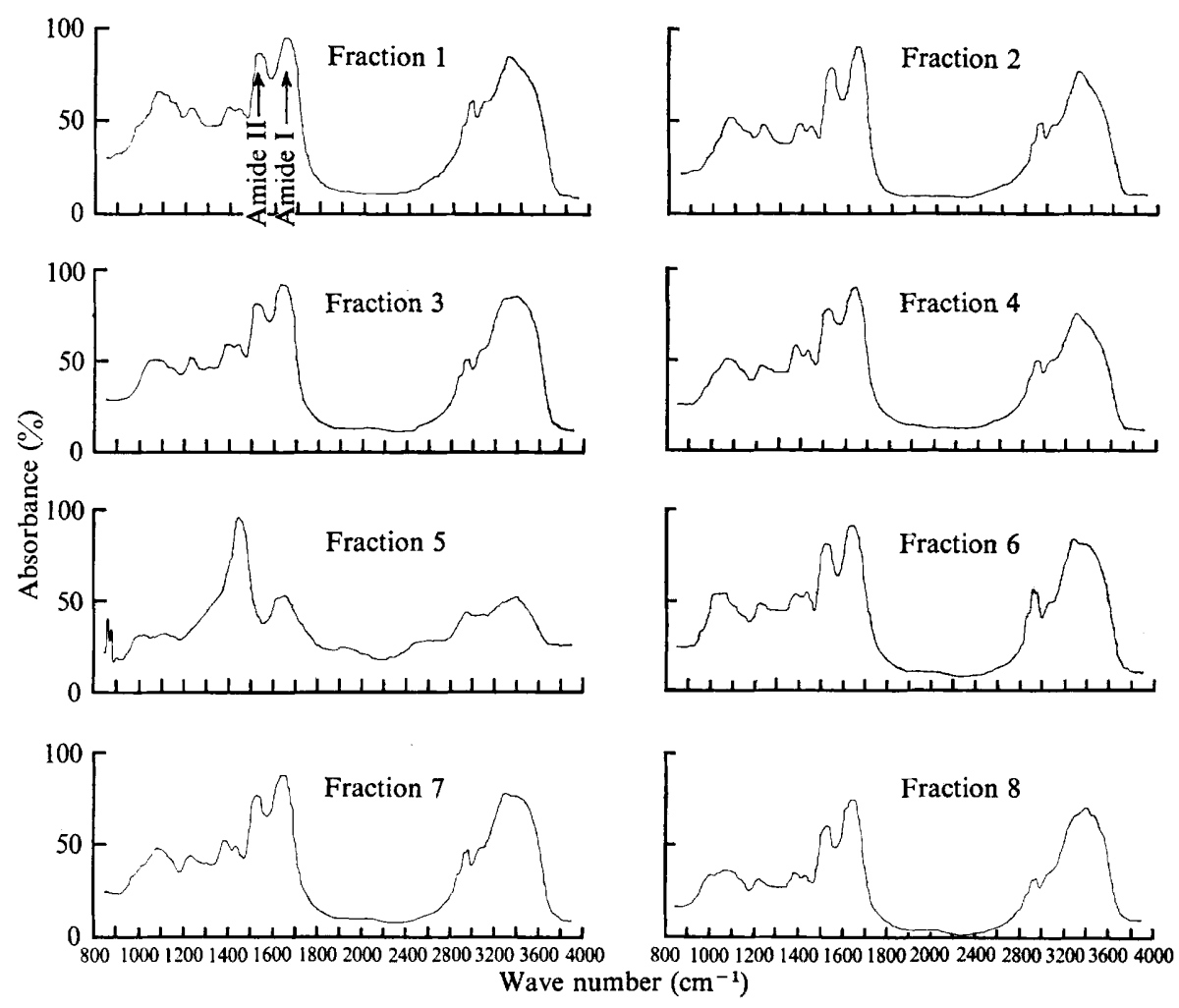

Fig. 3. Infrared absorption spectra of the coat fractions. The conditions employed were as follows: slit program, 1000; gain, 4.2; attenuator speed, I100; scan time, $16 \mathrm{~min}$; suppression, 6; scale, I; source current, $0.7 \mathrm{~A}$.

assignable), $3060 \mathrm{~cm}^{-1}$ (amide $\mathrm{B}, \mathrm{NH}$ stretching), and overlapped peaks near $2920 \mathrm{~cm}^{-1}$ and $2950 \mathrm{~cm}^{-1}$ were also found. The presence of peaks of amide I, amide II, amide A and amide B strongly suggests that the coat fractions, except fraction 5, contained peptides, although it is not clear whether the absorption was due to proteins or side chains of amino sugars.

As in the X-ray diffraction studies, fraction 5 exhibited quite different patterns from the other fractions. Apparently it did not contain peaks from peptide, amide I and II. These results indicate that fraction 5 was different from the others in structure and chemical composition. On the basis of these data, no further results on fraction 5 are described.

$N$-terminal amino acids. Ether soluble $N$-terminal DNP-amino acids detected by two dimensional t.l.c. are given in Table 2. Ten $N$-terminal DNP-amino acids were identified in every fraction. An attempt to compare the yields of the DNP-amino acids was not successful, since the molar ratios of the amino acids in each fraction were different on separate runs. Apparently, lysine, alanine, glycine and serine must have been among the $N$-terminal amino acids of the coat fraction materials, for they were always found in all the fractions.

The presence of so many kinds of $\mathrm{N}$-terminal amino acids indicates the complicated nature of the structure and composition of the coat. The results indicate that the spore coat contained several kinds of different peptides or proteins or both.

Amino acid composition of the fractions. As shown in Table 3 there was no significant difference in the amino acid composition of the fractions, and they resembled each other, suggesting that the coat fractions contained similar protein(s) or peptide(s). 
Table 2. Ether soluble $N$-terminal DNP-amino acids of coat fractions detected on two-dimensional thin-layer chromatography

Terminal amino acid

Fraction...

Lysine

Methionine

Leucine

Valine

Alanine

Glycine

Serine

Glutamic acid

Aspartic acid

Threonine

VS, Very strong; S, strong; M, medium; W, weak; VW, very weak; VVW, very very weak or not clearly identifiable.

Table 3. Amino acid compositions of coat fractions

\begin{tabular}{|c|c|c|c|c|c|c|c|}
\hline Amino acid & & & & ho aci & & & \\
\hline Fraction $\ldots$ & 1 & 2 & 3 & 4 & 6 & 7 & 8 \\
\hline Lysine & $8 \cdot 2$ & $8 \cdot 6$ & $4 \cdot 4$ & $6 \cdot 3$ & $4 \cdot 7$ & $4 \cdot 2$ & 5.6 \\
\hline Histidine & $4 \cdot 3$ & 3.9 & 3.0 & $3 \cdot 8$ & $2 \cdot 8$ & $3 \cdot 4$ & $2 \cdot 8$ \\
\hline Arginine & $4 \cdot 7$ & $4 \cdot 7$ & 44 & $4 \cdot 5$ & 4.0 & $4 \cdot 2$ & $3 \cdot 2$ \\
\hline Aspartic acid & $8 \cdot 8$ & I 1.0 & 10.9 & $I I \cdot I$ & I $1 \cdot 4$ & $9 \cdot 3$ & 10.0 \\
\hline Threonine & $5 \cdot 6$ & $5 \cdot 5$ & $5 \cdot 8$ & $5 \cdot 8$ & 5.9 & $5 \cdot 8$ & $6 \cdot 3$ \\
\hline Serine & $7 \cdot 7$ & $7 \cdot 0$ & $6 \cdot 4$ & $6 \cdot 6$ & $6 \cdot 5$ & $6 \cdot 9$ & 6.9 \\
\hline Glutamic acid & $8 \cdot I$ & $8 \cdot 6$ & $9 \cdot 0$ & $9 \cdot 3$ & 9.0 & $9 \cdot 6$ & $9 \cdot 3$ \\
\hline Proline & $1 \cdot 9$ & $3 \cdot 2$ & 3.4 & $3 \cdot 1$ & $3 \cdot 2$ & $3 \cdot 2$ & $1 \cdot 7$ \\
\hline Glycine & $16 \cdot 6$ & $13 \cdot 2$ & I6. I & 14.7 & $16 \cdot 2$ & 15.7 & 15.4 \\
\hline Alanine & $7 \cdot 7$ & $7 \cdot 3$ & $8 \cdot 2$ & $7 \cdot 8$ & $8 \cdot 2$ & $8 \cdot 3$ & $8 \cdot 2$ \\
\hline Half cystine & $2 \cdot 3$ & 3.5 & $I \cdot 9$ & $\mathrm{I} \cdot 7$ & $\mathrm{I} \cdot 7$ & $\mathrm{I} \cdot 8$ & $\mathrm{I} \cdot 8$ \\
\hline Valine & $6 \cdot 3$ & $5 \cdot 7$ & $6 \cdot 4$ & $6 \cdot 3$ & $6 \cdot 3$ & $7 \cdot 2$ & $7 \cdot 2$ \\
\hline Methionine & 0.4 & $\mathbf{I} \cdot \mathbf{I}$ & $I \cdot I$ & $1 \cdot 0$ & $1 \cdot 2$ & 0.8 & 0.1 \\
\hline Isoleucine & $3 \cdot 7$ & 4.0 & $4 \cdot 5$ & $4 \cdot 3$ & $4 \cdot 4$ & $4 \cdot 7$ & $4 \cdot I$ \\
\hline Leucine & $5 \cdot 3$ & $5 \cdot 5$ & $6 \cdot 4$ & 5.9 & $6 \cdot 1$ & $6 \cdot 5$ & $6 \cdot 2$ \\
\hline Tyrosine & $I \cdot 7$ & $2 \cdot 2$ & $2 \cdot 0$ & $2 \cdot I$ & $2 \cdot I$ & $2 \cdot 0$ & $4 \cdot 4$ \\
\hline Phenylalanine & 6.6 & $5 \cdot 1$ & $6 \cdot 1$ & $5 \cdot 8$ & $6 \cdot 2$ & $6 \cdot 3$ & $6 \cdot 8$ \\
\hline $\begin{array}{l}\text { Overall yield } \\
\text { based on weight } \\
\text { of sample }(\%)\end{array}$ & $41 \cdot 2$ & $54 \cdot 8$ & $47 \cdot 7$ & $54 \cdot I$ & $53 \cdot 9$ & $43 \cdot 4$ & $42 \cdot 8$ \\
\hline
\end{tabular}

The last line of the Table represents the estimated amino acid content, by weight, of the samples. Estimations of the amino acid contents of the samples, shown in the last line of Table 3, were made on the assumption that the amino acids composed a single peptide chain. As, also, the apparent weights of the hygroscopic coat fractions were overestimated due to the considerable amount of water adsorbed, these values express a minimum estimate of the contents.

The contents of (half) cystine as well as methionine were not high. Traces of methionine sulphoxide and/or hydroxyproline and some unidentifiable peaks were present.

Vinter (1959; 1960; 1961) showed that the spores of some Bacillus species (Bacillus megaterium, $B$. cereus, $B$. agrestis, $B$. mycoides and $B$. vulgatus) are rich in cystine plus cysteine and suggested these amino acids were localized in the coats. The maximum sulphur content 


\section{Table 4. Elemental analyses of certain coat fractions}

$\begin{array}{cccccc}\text { Fraction } & \mathbf{C} & \mathbf{H} & \mathbf{N} & \mathbf{P} & \mathrm{S}^{*} \\ \mathrm{I} & 42 \cdot 12 & 6.76 & \mathbf{I 2 \cdot 9 7} & 0.12 & \mathrm{I} \cdot 08 \\ 3 & 45 \cdot 33 & 6 \cdot 72 & \mathbf{I 2 . 3 3} & 0.43 & 0.88 \\ 6 & 47 \cdot 19 & 6.30 & 13.53 & 0.46 & 0.87 \\ 8 & 43.65 & 6.17 & \mathbf{1 3 . 2 8} & \mathbf{I} \cdot 45 & 0.80\end{array}$

* Values are overestimated owing to the presence of $P$.

of the coats was $4 \mathrm{I} \mu \mathrm{g} / \mathrm{mg} N$. This value corresponds to a cystine content of $\mathrm{I} \cdot 8 \%$, if it be assumed that all the sulphur was derived from cystine and the amino acids include only one $\mathrm{N}$-atom/molecule. This cystine content and those in alkali-soluble fraction, resistant residue of B. megaterium QMBI55I (Kondo \& Foster, 1967) and in the coat of B. cereus $\mathrm{T}$ (Aronson \& Fitz-James, 1968) are similar to that in the present experiments.

Elemental analyses of the coat fractions. The hydrogen, carbon, nitrogen, phosphorus and sulphur contents were similar for all fractions (Table 4). The nitrogen contents were very similar to those of some Bacillus species (Strange \& Dark, 1956; Warth et al. 1963; Murrel, 1967).

The sulphur contents of the fractions were not so accurate. The presence of phosphorus increases the apparent content of sulphur, so true contents of sulphur may be lower than the values shown in Table 4. Making the assumption described above, cystine plus methionine contents were $3.6 \%$ in fraction $1,3.1 \%$ in fraction $3,2.8 \%$ in fraction 6 and $2.6 \%$ in fraction 8.

Electron microscopy of the coat fractions. Photographs of the sectioned and shadowed replica of an intact spore (Fig. 4 to 6) exhibited several morphological features of the spore coat. As is seen in Fig. 4 the coat was clearly distinguishable from the cortex. The coat consisted of three parts: (i) the inner part commonly designated as 'inner coat' (Murrel, 1967; Gould \& Hurst, 1969), (ii) the outer part designated 'outer coat' and (iii) a region located outside the outer coat and currently called 'surface layer' (Fig. 4, 5). When stained deeply with osmium tetroxide $\left(\mathrm{OsO}_{4}\right)$, the inner coat exhibited a laminar structure, but it seemed structureless when treated moderately with $\mathrm{OsO}_{4}$ or glutaraldehyde (Fig. 5). The outer coat seemed electron opaque when stained deeply with $\mathrm{OsO}_{4}$ (Fig. 4), probably because of overstaining, but it could also appear laminated (Fig. 5, 7). There was no morphological difference between inner and outer coat. The chemical affinities of both coats to $\mathrm{OsO}_{4}$ and glutaraldehyde were not the same; the surface layer seemed less stainable than the outer coat. It is not clear at present whether the 'surface layer' was a part of the spore coat or an exosporium.

The parallel straight streaks on the surface of the spore and spore coat are seen in Fig. 6 , 9, I0. This appearance may correspond to the fibres which appear to exist on the surface of the 'exosporium' of the freeze-etched preparation of Bacillus subtilis w23s ${ }^{x}$ (Holt \& Leadbetter, 1969) or to what is called 'decoration' in the field of surface physics, which reflects the properties of underlying layers (outer coats). This appearance was preserved through all treatments. The sections of the fractions also do not differ much in appearance, but a part of the inner coats may have been removed by pronase treatment (see Fig. 8).

Attempts to solubilize the coat. Coats were treated at room temperature and at $70{ }^{\circ} \mathrm{C}$ with I M-KOH, $5 \mathrm{M}-\mathrm{KOH}$, absolute ethanol, absolute acetone, formic acid (99 to $100 \%, \mathrm{w} / \mathrm{w}$ ), dichloroacetic acid (DCA, more than $90 \%$ w/w), dioxane, chloroform, acetic acid (99 to $100 \%, \mathrm{w} / \mathrm{w}), \mathrm{LiBr}(60 \%, \mathrm{w} / \mathrm{w}), 4 \mathrm{M}$-guanidine $\mathrm{HCl}$, and $8 \mathrm{M}$-guanidine $\mathrm{HCl}$. Among the 

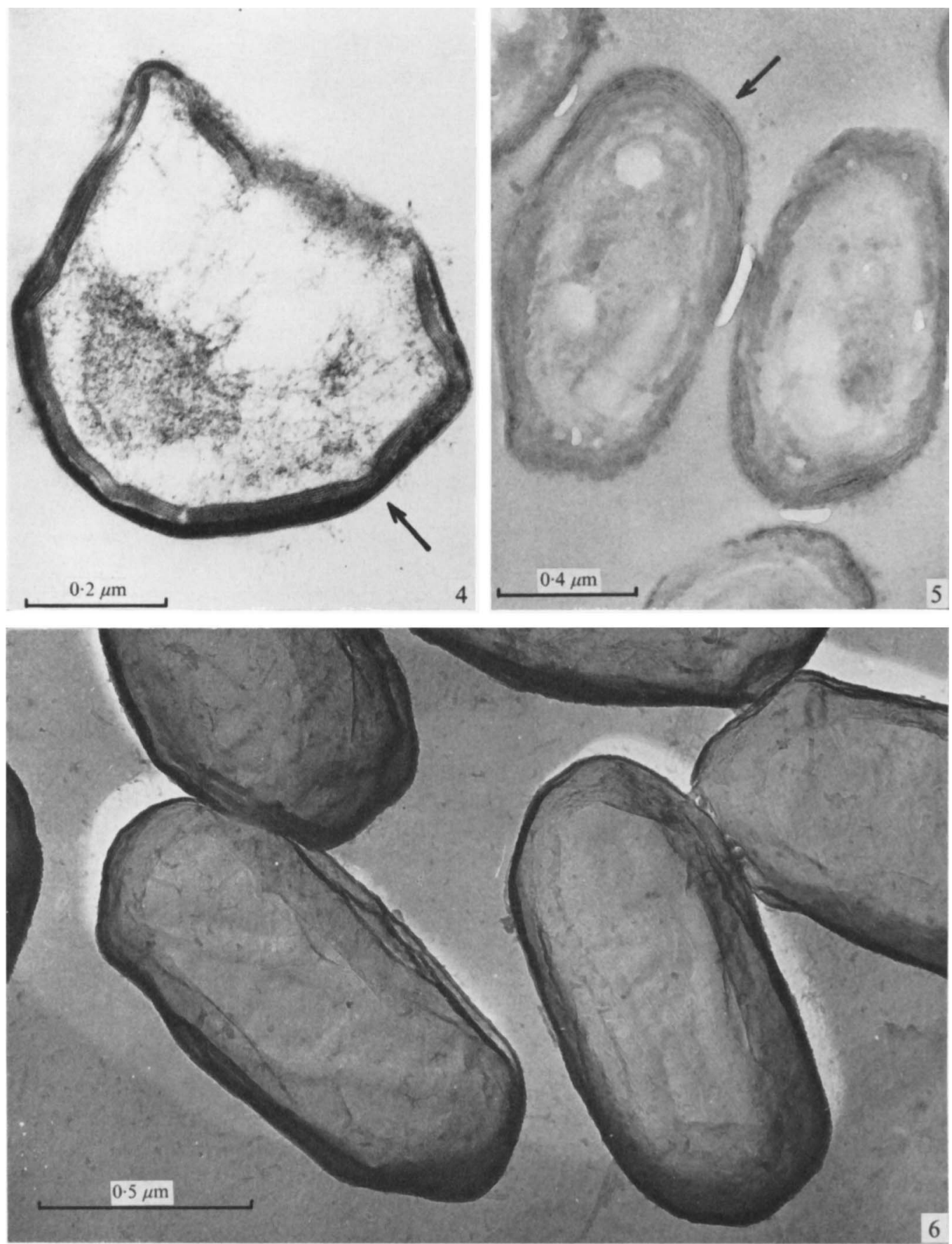

Fig. 4. An electron micrograph of the section of the intact spore after fixation with $\mathrm{OsO}_{4}$. Boundary of the laminar inner coat and cortex is very clearly seen. Surface layer (arrow) is visible outside of the electron opaque outer coat.

Fig. 5. An electron micrograph of the section of intact spore after glutaraldehyde fixation. Boundary of the inner coat and cortex is not clear in this case. Laminar structure of the outer coat is visible together with surface layer (arrow).

Fig. 6. An electron micrograph of the shadowed replica of the intact spore. Parallel streaks are seen on the surface of the spore. 

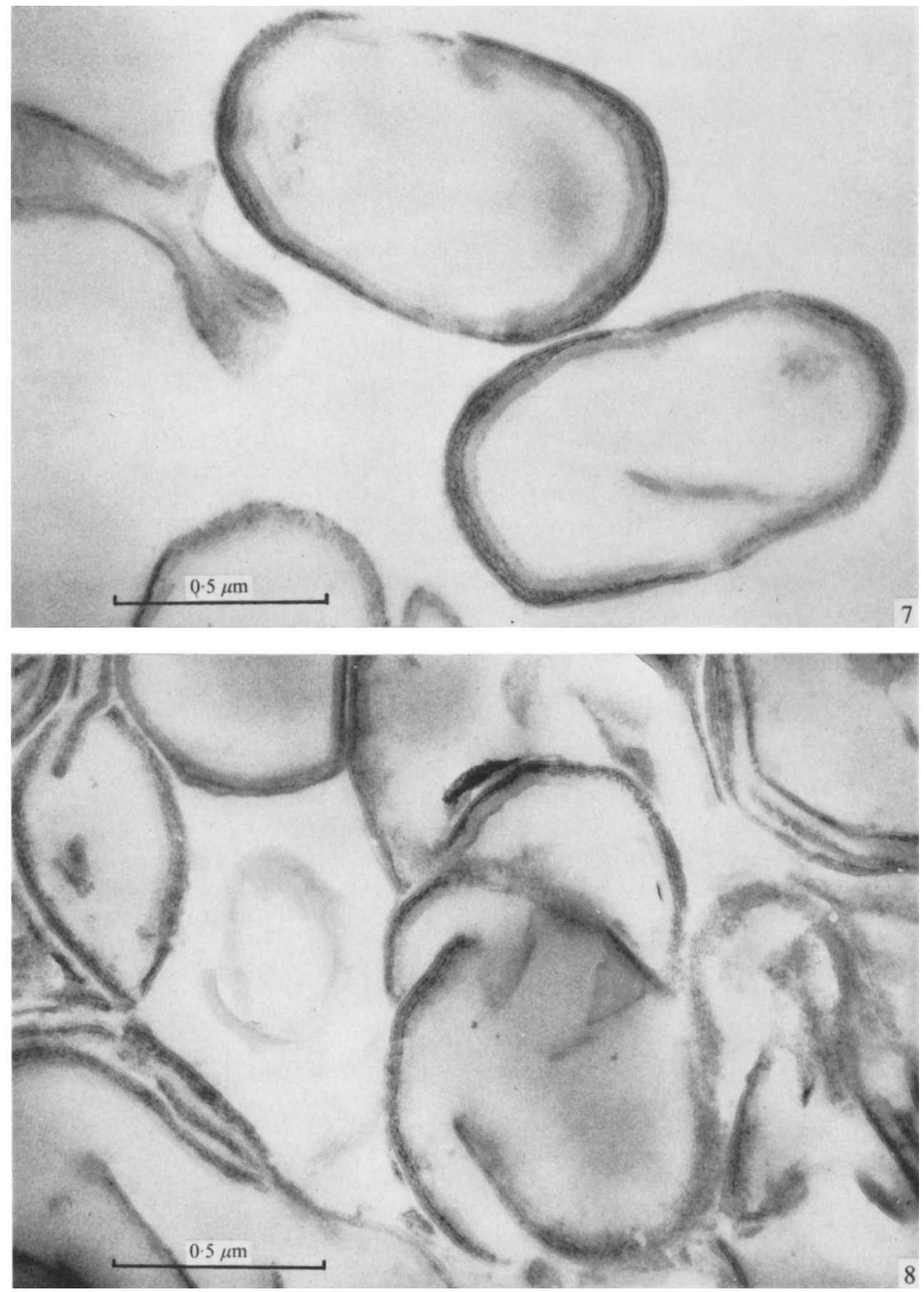

Fig. 7. An electron micrograph of the section of fraction 2 after moderate fixation with $\mathrm{OsO}_{4}$.

Fig. 8. An electron micrograph of the section of fraction 8 after moderate fixation with $\mathrm{OsO}_{4}$. Laminar structure is still preserved, although a part of inner coat and surface layer seem to be removed. 

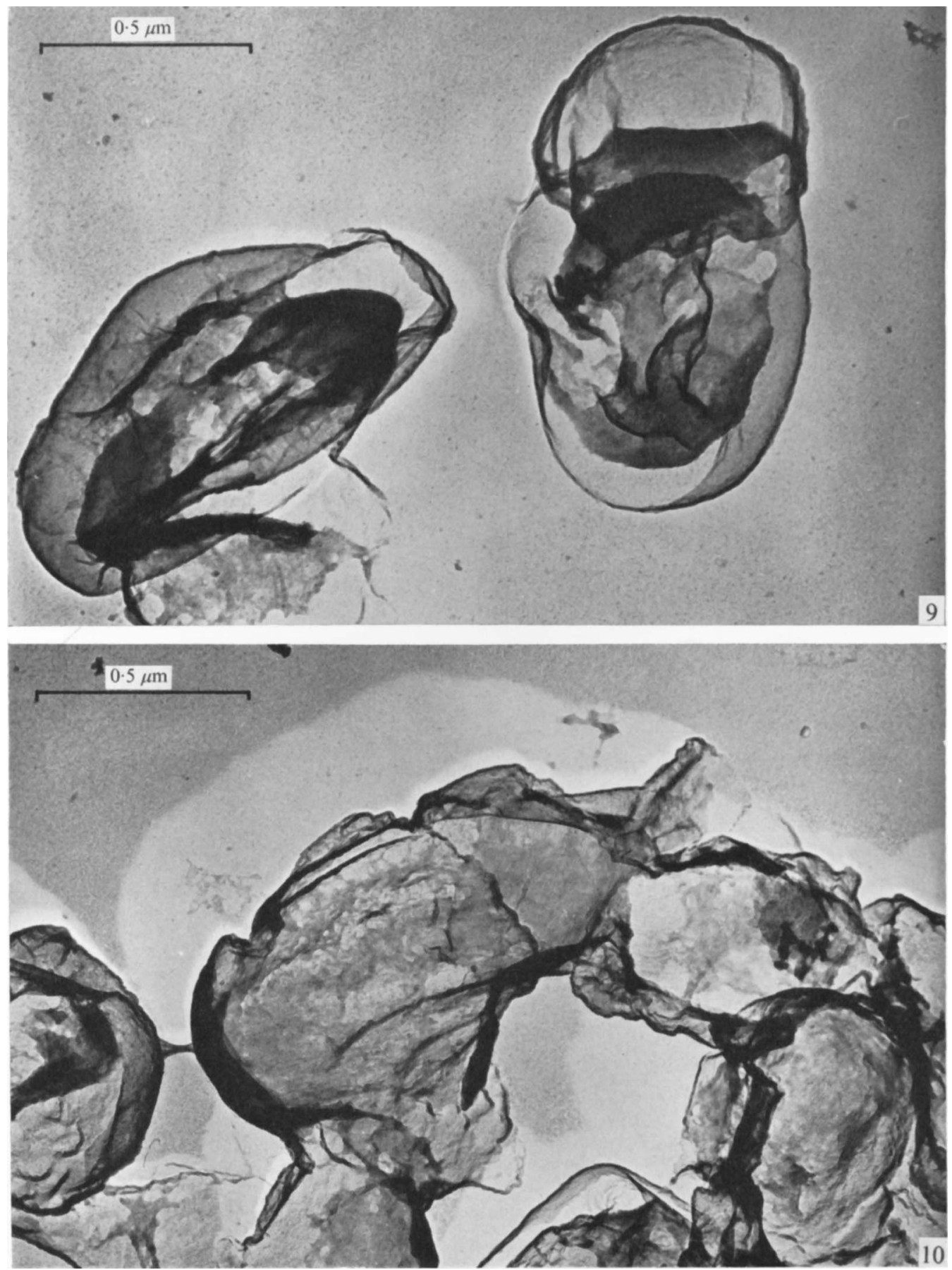

Fig. 9. An electron micrograph of the shadowed replica of fraction 2.

Fig. 10. An electron micrograph of the shadowed replica of fraction 8 . No large alteration in surface structure was seen. Parallel streaks are still visible. 
above treatments, the coats were dissolved only in DCA at both room temperature and $70^{\circ} \mathrm{C}$. The coats were not dissolved in reagents which caused phase darkening (Gould \& Hitchins, 1963) in accord with their observation that the spore left the coat material. Dithiothreitol and 2-mercaptoethanol, disulphide-bond-breaking reagents, did not dissolve the coat.

A solution of cleaned spore coat (I00 $\mathrm{mg}$ ) in DCA $\left(40 \mathrm{ml}\right.$, at $\left.70^{\circ} \mathrm{C}\right)$ gave a tan colour. After centrifugation at $13000 \mathrm{~g}$ for $30 \mathrm{~min}$, the sediment was resuspended in DCA ( $15 \mathrm{ml}$, at $70^{\circ} \mathrm{C}$ ). Solubilization and centrifugation were repeated until the supernatant fluid was colourless. The final residue weighed $6 \mathrm{mg}$, i.e. $94 \%$ of the coat was dissolved in DCA. Since some of the insoluble matter might have been lost in the supernatant, the true solubility of the coats could be several percent lower than this value. The material soluble in DCA could not be transferred into any other solvent tried so far because of precipitate forming, and further investigation of the chemical and physical properties of the material was not undertaken.

Comparison of keratins with spore coat. To compare the spore coat with keratins from hair, wool and human finger nail, keratins were treated with DCA and DCA plus peracetic acid. They were not soluble in pure DCA. They were solubilized in DCA plus peracetic acid within $24 \mathrm{~h}$ (human nail) or in a few days (human hair and wool). This result suggests that for the solubilization of keratins, unlike the spore coat, the rupture of the disulphide bond is indispensable (Crewther, Fraser, Lennox \& Lindley, 1965). The chemical nature of the spore coat apparently did not resemble that of keratins.

Amino sugar test. The Elson-Morgan reaction (Elson \& Morgan, 1933) on fraction 8 showed that amino sugars were still contained in the fraction.

\section{DISCUSSION}

The freeze-etching study of Holt \& Leadbetter (1969) showed that there was a tissue which was different from outer coat and located outside the spore coat; the authors called this tissue exosporium. The surface layer observed in this work might correspond to the exosporium of the freeze-etching micrographs. However, the present results suggest that the coat fractions except fraction 8 still retain most of the surface layer in spite of rather harder treatment. Since the exosporium seems to be removed more easily than spore coat in the case of Bacillus cereus (Gerhardt \& Ribi, 1964), the tissue discussed here would be more similar to coat than exosporium.

The results of X-ray diffraction, i.r. spectra, amino acid analyses, $N$-terminal amino acids and elemental analyses suggested that the fractions except fraction 5 are very similar in chemical constitution and in structure. Electron microscopic observations of the fraction showed that no treatment caused material alteration of the morphological structure of the spore coat and it seems that the coat material was gradually removed from inner to outer as the treatments proceeded. Similar observations were made on Bacillus megaterium QMBI 55 I by Kawasaki, Nishihara \& Kondo (I969). From these observations, it is suggested that the coat of $B$. subtilis is chemically and structurally similar in all parts. This interpretation, however, might be contradictory to the observation that the inner coat, outer coat and surface layer are stained differently with $\mathrm{OsO}_{4}$ (see Fig. 4). One explanation is that, even though components of the coat have the same chemical and molecular structure, they would not be the same at a higher level (for example molecular packing) and, therefore, they were stained differently.

Cystine was not plentiful in any of the fractions throughout the present work. The cystine 
plus methionine contents estimated from $\mathrm{S}$ contents were not very high. If we take into account of the presence of histidine, lysine etc., which have more than two nitrogen atoms in a molecule, the increase in the corrected values of the cystine plus methionine contents does not exceed about one and half times the values shown in the results of elemental analyses. These values are lower than the least cystine content in keratins (Crewther et al. 1965), despite the content of S being over-estimated in the present elemental analyses. Most of the values for cystine (or cystine plus methionine) content reported so far by other authors using various methods have been similar. Present solubilization experiments also suggest that the chemical nature of the spore coat differs somewhat from that of keratins. These observations do not seem to be in favour of the view that coat consists of keratin-like proteins.

The author is grateful to Professor H. Kadota and Dr A. Uchida for microbiological techniques, and Dr M. Oikawa and Mr T. Matsuo for electron microscopy. The interest and support of Professor T. Ooi, and discussions and suggestions of Dr S. Takahashi in this work are gratefully acknowledged.

\section{REFERENCES}

Aronson, A. I. \& Fitz-JAmes, P. C. (1968). Biosynthesis of bacterial spore coats. Journal of Molecular Biology 33, I99-2 I 2.

Asa, M., Tsuboi, M., Shimanouchi, T. \& Mizushima, S. (1955). Infrared spectra of polypeptides and related compounds. I. Journal of the American Chemical Society 59, 322-325.

Crewther, W. G., Fraser, R. D. B., Lennox, F. G. \& Lindley, H. (1965). The chemistry of keratins. In Advances in Protein Chemistry, 20, 191-346.

ELL1OT, A. (1954). The infra-red spectra of some optically active and meso-synthetic polypeptides. Proceedings of the Royal Society of London A 22r, r04-II4.

Elson, L. A. \& Morgan, W. T. J. (1933). A colorimetric method for the determination of glucosamine and chondrosamine. Biochemical Journal 28, 1824-1828.

GeRHARDT, P. \& RiBI, E. (I964) Ultrastructure of the exosporium enveloping spores of Bacillus cereus. Journal of Bacteriology 88, 1774-1789.

Gould, G. W. \& Hitchins, A. D. (1963). Sensitization of bacterial spores to lysozyme and hydrogen peroxide with reagents which rupture disulphide bonds. Nature, London 197, 622.

Gould, G. W. \& HURST, A. (1969). In The Bacterial Spore. (Frontispiece.) London: Academic Press.

Holt, S. C. \& LeADBetrer, E. R. (1969). Comparative ultrastructure of selected aerobic spore-forming bacteria: a freeze-etching study. Bacteriological Reviews 33, 346-378.

Kadota, H. \& Iisima, K. (1965). The X-ray diffraction pattern of spores of Bacillus subtilis. Agricultural and Biological Chemistry 29, 80-81.

Kadota, H., InImA, K. \& UCHIDA, A. (1965). The presence of keratin-like substance in spore coat of Bacillus subtilis. Agricultural and Biological Chemistry 29, 870-875.

KaWASAKI, C., NishiHaRA, T. \& KonDo, M. (1969). Ultrastructure and its relation to the fractions isolated from spore coat of Bacillus megaterium. Journal of Bacteriology 97, 944-946.

Kondo, M. \& Foster, J. W. (1967). Chemical and electron microscope studies on fractions prepared from coats of bacillus spores. Journal of General Microbiology 47, 257-271.

Miyazawa, T. \& Blour, E. R. (1961). The infrared spectra of polypeptides in various conformations: amide I and II bands. Journal of the American Chemical Society 83, 712-719.

Murrel, W. G. (1967). The biochemistry of the bacterial endospore. In Advances in Microbial Physiology, vol. I, pp. 133-251. Edited by A. H. Rose and J. F. Wilkinson. London: Academic Press.

SACKS, L. E. \& AlderTon, G. (I96I). Behaviour of bacterial spores in aqueous polymer two-phase systems. Journal of Bacteriology 82, 33I-34I.

Salton, M. R. J. \& Marshall, B. (1959). The composition of the spore wall and the wall of vegetative cells of Bacillus subtilis. Journal of General Microbiology 21, 415-420.

Strange, R. E. \& Dark, F. A. (1956). The composition of the spore coats of Bacillus megaterium, B. subtilis and B. cereus. Biochemical Journal 62, 459-465. 
VINTER, V. (1959). Difference in cyst(e)ine content between vegetative cells and spore of Bacillus cereus and Bacillus megaterium. Nature, London $\mathbf{1 8 3}$, 998-999.

VINTER, V. (1960). Spores of micro-organisms VIII. The synthesis of specific calcium and cystine-containing structures in sporulating cells of Bacilli. Folia microbiologica 5, 217-230.

VINTER, V. (I961). The formation of cystine-rich structure in sporulating cells and its possible role in the resistance of spores. In Spores, vol. Ir, pp. I27-141. Edited by H. O. Halvorson. Minneapolis: Burgess Publishing Co.

WARTh, A. D., OHYE, D. F. \& MURELL, W. G. (1963). The compositions and structure of bacterial spores. Journal of Cell Biology 16, 579-592. 